\title{
Materiales (de)construcción. Crítica, neoliberalismo e intervención social.
}

Borja Castro-Serrano, Alex Cea y Nelson ArellanoEscudero (editores). Nadar Ediciones, Santiago de Chile, 2020. ISBN 978-956-9552-26-7

Marcela Flotts de los Hoyos*

La publicación de este libro, tal como enuncian sus editores en la presentación, coincide con un momento histórico en Chile. Y no solo por las extrañas circunstancias en que nos encontramos a raíz de la pandemia, sino especialmente porque en el país estamos siendo testigos de procesos sociales que han permitido avanzar hacia aquello que tanto requiere la transformación social: modificaciones en aquellos imaginarios colectivos que reproducen la naturalización de las consecuencias extremas del duro neoliberalismo instalado en Chile durante la dictadura militar.

Entre aquellas consecuencias considero sin duda las profundas desigualdades sociales, la enorme concentración de la riqueza, la desaparición del Estado en variados ámbitos de la vida de las personas, el rol exagerado del mercado para regular la vida social y la pérdida de lazos colectivos, entre otros efectos que la consolidación del sistema neoliberal ha traído para Chile.

En palabras de los editores, el libro "es una constelación de constataciones de la dura realidad de la desigualdad, la injusticia, faltas a la dignidad y búsquedas de respuestas ante la brutalidad que se despliega aún en este primer cuarto del siglo XXI, cuando ya hemos comprobado que los cantos de sirena del siglo XX, que prometían mejor vida desde año el 2020, se han desvanecido o convertido en la rabia expresada en las revueltas de octubre y noviembre de 2019 (...)" (p. 26).

Trabajadora Social y Dra. en Ciencias Sociales. Directora de Aseguramiento de la Calidad, Facultad de Educación y Ciencias Sociales, UNAB. E-mail: mflotts@unab.cl 
Por ello, celebro este libro y a sus autoras y autores. Ofrece un espacio de reflexión claramente contingente y altamente pertinente para resignificar los procesos de intervención social hoy en el país. Este año, los chilenos y las chilenas decidiremos sobre la posibilidad de una nueva Constitución y el libro gira, conceptualmente, en torno a algo similar: así como desmontar la carta fundamental de la República abrirá la posibilidad de pensar un Chile más justo, menos desigual y más solidario, el libro abre la posibilidad de deconstruir lo social y las formas en que hemos pensado y actuado sobre lo social, y así promover procesos de transformación que resguarden la igualdad, la justicia y la dignidad.

La tríada conceptual propuesta en el título - a saber, crítica, neoliberalismo, intervención social - apunta justamente a ello. Bajo el prisma conceptual de Derrida, el libro se plantea entender que los distintos conceptos de crítica "desmontan y/o denuncian la normatividad social dominante, pero al mismo tiempo, deslizan o proponen algún criterio o sentido que sirva como horizonte de construcción de un mundo más justo" (p. 18). ¿ No es acaso una tremenda apuesta para leer y comprender las complejidades de lo que sucede en Chile hoy? Así, pareciera que el libro sintoniza con el sentir más profundo del movimiento social: denunciar una normatividad social que genera crudas desigualdades en nuestra sociedad y visualizar nuevos sentidos que promuevan la justicia.

Lo hace de un modo tan atrevido como interesante, ya que se basa en la reflexión de autores y autoras con disciplinas y trayectorias profesionales diversas, en propuestas capturadas desde diferentes lugares teóricos y en "un pensar sin disciplina" (p. 21). Esto provoca que la lectura del texto permita expandir los bordes disciplinarios, para pensar críticamente la intervención social en un contexto marcadamente neoliberal.

Dichas reflexiones se organizan en dos grandes apartados. El primero, denominado "Neoliberalismo, catástrofe e intervención social", reúne tres contundentes capítulos en los que resaltan las inquietudes relacionadas con la comprensión crítica de la intervención social en el ya mencionado contexto neoliberal. Este último cobra una particular relevancia en las propuestas de Gianinna Muñoz-Arce, Ángelo Nar- 
váez León, Pablx Salinas Mejías y Nelson Arellano-Escudero, las y los autores de estos primeros tres capítulos.

El segundo apartado, "Teorías críticas e intervención social”, organiza cuatro capítulos en los cuales la noción de "intervención social" es la que cobra protagonismo, para anclarla en posturas teóricas que permiten la complejización de sus sentidos y alcances. Alex Cea Cea, Alejandro Castro, Natalia Hernández Mary, Borja Castro-Serrano, Cristian Ceruti Mahn y Cristian Fernández Ramírez ofrecen, en sus respectivos capítulos, potentes miradas sobre la intervención social.

Al leer estos siete capítulos, más la presentación de los editores y el epílogo de María Eugenia Hermida, las palabras de Borja, Alex y Nelson cobran total sentido: “(...) a los lectores que tengan este artefacto en sus manos, podemos advertirles que, en tanto libro que pretende tensionar la noción de intervención social, permitirá que encuentren en él distintos enfoques teóricos, aunque inscritos en lugares conceptualmente bien definidos (...)" (p. 20).

En síntesis, invito con entusiasmo a leer Materiales (de)construcción. Crítica, neoliberalismo e intervención social. E invito a hacerlo desde claves de lectura similares a las de las demandas colectivas que clama hoy la sociedad chilena (o gran parte de ella), es decir, con la convicción que la deconstrucción social permitirá ver la precariedad de nuestro sistema en términos de dignidad, igualdad y justicia. 